Martin, R. P., Newbould, P. \& Russell, R. S. (1957). International Conference on Radioisotopes in Scientific Research, Paris. UNESCO/NS/RIC/175.

Newcombe, H. B. (1957). Science, 126, 549.

\title{
Nutritional hazards caused by radioactive contamination of foods
}

\author{
By G. B. S. Heath, Ministry of Agriculture, Fisheries and Food, \\ Veterinary Investigation Centre, Penrith
}

The hazards which may exist as a result of the contamination of herbage by radioactive material will depend upon the degree of contamination and the active isotope or isotopes concerned. It is proposed, therefore, to summarize briefly the way in which fallout from a bomb may affect a crop.

\section{Isotopes that may contaminate crops}

Fallout may be made up of a hundred or more active isotopes but only a few of them are likely to be harmful as crop contaminants.

Iodine. As ${ }^{131} \mathrm{~T}$, it will be a major hazard for a few weeks after fallout arrives. Chamberlain \& Chadwick (1953) showed that iodine gas is deposited on grass by diffusion. Chamberlain, Loutit, Martin \& Russell (1955) note that, in fresh fission products, the iodine hazard will be increased since the short-lived isotopes ${ }^{132} \mathrm{I}$, ${ }^{133} \mathrm{I}$, and ${ }^{135} \mathrm{I}$ will make a considerable contribution. The maximum permissible concentration on herbage is well below that needed for external radiation hazards (Parker, I950).

Caesium. Much has been heard about the possible effect of ${ }^{137} \mathrm{Cs}$ but it is difficult to assess the dangers that may be associated with this isotope. Ingested caesium is well absorbed and a high concentration develops in muscles (Hood \& Comar, I953). Thus, apart from possible damage to the health of animals, ingestion of ${ }^{137} \mathrm{Cs}$ may render the animal useless as a source of meat. On the other hand, caesium is not readily taken up from the soil by plants (Anderson, Schuch, Fisher \& Langham, 1957) and its biological half-life is fairly short-140 days in man and 20 days in cattle. It might be wise to regard ${ }^{137} \mathrm{Cs}$ as a hazard of unknown degree.

Strontium. There is no doubt whatever about the dangers associated with contamination of crops by ${ }^{89} \mathrm{Sr}$ and ${ }^{90} \mathrm{Sr}$. Lapp (1955) points out that radiostrontium (a) has a long half-life, (b) is born with a high fission yield, (c) because of its gaseous predecessor, diffuses throughout the fireball of a thermonuclear explosion and 'plates' upon the debris, (d) resembles calcium and is thus subject to uptake in biological systems and (e) is a bone-seeker and, because of it, its $\beta$-rays are of considerable biological significance. Lapp also stresses the fact that, weight for weight, ${ }^{89} \mathrm{Sr}$ is $\mathrm{I} 80$ times more radioactive than ${ }^{90} \mathrm{Sr}$; this higher activity is associated with its shorter half-life. From published figures, he calculates that a I0-megaton thermonuclear bomb might deposit $2-3 \mathrm{~g}$ radiostrontium/sq. mile, and this tiny weight of 18 (1) 5 
material would give an activity of about $10 \mu \mathrm{c}{ }^{90} \mathrm{Sr} / \mathrm{sq}$. ft. and $\mathrm{I} \cdot 5 \mathrm{mc}{ }^{89} \mathrm{Sr} / \mathrm{sq}$. ft. This amount, by any standard, is high and far in excess of the maximum permissible level suggested by Chamberlain et al. (1955).

For practical purposes, then, we may conclude that radioiodine and radiostrontium are the nuclides that will cause the most harm if they contaminate crops.

\section{Contamination of crops}

The crops themselves are very resistant to the effects of radiation. Outside the area of total destruction there will probably be little effect upon the growth of plant life. Sparrow \& Christensen (1953) found that even the most sensitive species could withstand chronic exposures of $30-40 \mathrm{r} / \mathrm{day}$, and, at the other extreme, gladioli grew well when exposed to $6000 \mathrm{r} /$ day. It is probable that most farm crops could withstand up to $5000 \mathrm{r}$ spread over a day or so, and low doses subsequently, without having their growth markedly affected. Where animal life can continue there will probably be no visible damage to crops. But genetic damage in plants may be considerable even with quite low doses. Brown (1950) found irregularities in chromosome pairing in plants grown from seed exposed to an actual bomb explosion. Singleton (1955) found that chronic exposures to more than $5 \mathrm{r} /$ day definitely increased the mutation rate.

Crops are normally grown for domestic animals or man to eat, which brings us to the more serious effects of contamination by radioactive materials. The hazards involved can be considered when we have found out what happens to the isotopes after they have fallen on the crops. Comar, Russell \& Wasserman (I957) and others found that a portion of fallout which settles on leaves is absorbed by the plant. Also, since fallout is not easily washed off herbage by rain it is certain that growing crops that have been contaminated will remain dangerous for a considerable time. It is important to remember that fallout on plants is not likely to be visible. The U.S. Atomic Energy Commission (1950) showed that solutions of salts produced by fission can be dried on sand or metal powder to form a powder which would be quite lethal if spread on the ground at the rate of $12 \mathrm{mg} / \mathrm{m}^{2}$, and this contamination would be completely invisible.

The grazing habits of livestock are a complicating factor in assessing the danger of fallout on herbage. A cow grazes about 300 sq. yd. every day and will quickly concentrate fallout from a big area into her own body.

\section{Contamination of soil}

Contamination of soil by radioactive material is more important than surface contamination of leaves. It is impossible to lay down hard-and-fast rules about the uptake of fission products since their availability to the plant depends upon their solubility. But, although some forms of fallout would be taken up by the plants more easily than others, most of it would be taken up to some extent. Strontium will be the most important contaminant and a great deal of work has been done to find out the amount of radiostrontium that plants will remove from the soil. The problem is far more complex than it appears to be at first sight but, for our purposes, 
it is sufficient to say that plants may absorb about $2 \%$ of the radiostrontium in the soil and that concentrations in the leaves and stems will be much greater than in fruiting parts.

\section{Effects of radiation on animals}

The above rather blurred survey of existing knowledge suggests that explosion of a thermonuclear bomb or an industrial accident might contaminate crops with radioiodine and radiostrontium, and that crops grown on soil contaminated by radiostrontium might contain harmful amounts of the active isotope.

Extensive experience with $\mathrm{X}$-rays and radium has produced much of our knowledge of the effects of ionizing radiation. For reasons not yet clear, the effectiveness of different types of radiation cannot be calculated from their relative ionizing powers and must be determined experimentally. It can be said, however, that the immediate manifest effect of all known high-energy radiations in biological tissue consists of ionization and excitation. The biological effects that follow are basically mutations and chemical changes in the cell. These fundamental effects may result in impairment of normal function or death of a cell or groups of cells.

Tissues vary enormously in their sensitivity to radiation. Bone-marrow and lymph nodes are most sensitive, followed in order by the gastro-intestinal tract, gonads, skin and mucous membrane; muscles, nerves and peripheral blood are relatively resistant (Loutit \& Russell, 1955). This overall susceptibility of tissues is, of course, upset by radioiodine which is concentrated in the thyroid gland; it is thus possible to ablate the thyroid by oral doses of ${ }^{131} \mathrm{I}$ without causing apparent damage to the rest of the body.

The nutritional hazards of contaminated foods cannot be separated from the effect of external radiation because it is obvious that an animal grazing a contaminated pasture must be exposed to some external radiation but, for purposes of this paper, external radiation will not be considered.

It will be convenient to consider the hazard of freshly contaminated crops separately from that of a crop grown on soil contaminated by radiostrontium because the effects may be very different.

The signs associated with ingestion of radioactive food can all be related to the effects of radiation which have already been described. Because the life of a white blood cell is short-a few hours to a few days-any damage to the bone marrow and lymph nodes is quickly reflected by development of leucopenia. Thrombocytes also live for only a few days and bleeding may be extensive. After being damaged, or as a result of normal wear and tear, mucous membranes and skin fail to renew themselves and the process may lead to ulceration; entry of bacteria is made easy.

\section{Radiation sickness}

Acute. Clinicians will find little difficulty in deducing the picture presented by an animal that has eaten big quantities of radioactive material. Ulceration permits entry of bacteria to the blood stream - and there are very few leucocytes to fight them; death from septicaemia is almost inevitable. Ulceration exposes blood vessels to 
damage, and there are insufficient thrombocytes to promote clotting; extensive bleeding is a constant feature. Diarrhoea is a prominent sign and may be entirely due to intestinal damage, though there may be other causes.

The clinical picture may well be described by saying that it is identical with that of bracken poisoning. Since aplasia of the bone marrow is prominent in both conditions, this similarity is not surprising. Consideration of the literature suggests that a period of apathy lasting for a few days might be succeeded by diarrhoea, bleeding, and pyrexia due to non-specific infection. Death would follow in less than 2 weeks.

Subacute. Signs are similar to those of the acute disease. Anorexia, general malaise, pyrexia and emaciation are followed by death or slow recovery in about 4 weeks. Loutit \& Russell (I955) state that injury to the skin may become apparent by loss of hair, which may be a useful clinical sign with animals that have received a dose less than $\mathrm{LD}_{50}$.

Sublethal. Anorexia and emaciation may be accompanied by slight bleeding but recovery would be expected in a few weeks.

Treatment. Treatment of cases showing clinical signs would probably be useless if it were necessary to continue to feed the animals on contaminated material. Clean food, good nursing, and judicious use of antibiotics would probably save many animals. Treatment with splenic extracts might be of value in raising the level of deoxyribonucleic acid, but this work is still in the experimental stage.

\section{Genetic effects}

The literature is confused about possible genetic effects of exposure to radiation. Wright (1950) states: 'A strong possibility exists that cumulative doses of $300 \mathrm{r}$ may have important effects on the off-spring and descendants of those affected and that doses as small as $30 \mathrm{r}$ may not be negligible.... There are such enormous gaps in the knowledge of the subject that no judgements of the genetic consequences of radiation in man can be taken very seriously'. The statement probably still holds good for domestic animals.

\section{Disease produced by crops grown on contaminated soil}

It has been pointed out that $\mathrm{Sr}$ will probably be the major hazard in crops grown on soil contaminated with fallout. Crops that have had fresh fallout deposited on them may contain vast amounts of many nuclides. Crops grown on contaminated soil will probably contain small amounts of Sr. In metabolism, Sr follows the path of $\mathrm{Ca}$; it is excreted in the milk and is stored in the bones. Because it gives off $\beta$-radiation, it is very damaging. In big doses, it might produce bone-marrow aplasia, but doses will probably be small, and osteitis, leukaemia, and sarcomata are the probable effects that will be seen. Many types of malignant disease might occur but, if contaminated pastures were used for animals that would soon be killed, these conditions might not have time to occur. Also, if crops were removed from these fields and used as fodder in areas where fallout had not occurred, dilution with other foods as well as the decay that would occur before feeding might render them safe. 


\section{Food inspection}

The carcasses of animals that have to be slaughtered after eating contaminated food can often be salvaged. Bones and viscera would normally have to be discarded but the flesh should be all right, unless ${ }^{137} \mathrm{Cs}$ had been eaten in dangerous quantities. At other times, the normal rules governing meat inspection would apply. Milk from animals that had been eating contaminated crops would be expected to contain radioiodine and radiostrontium and should only be released for sale as liquid milk if monitoring showed it to be safe. Butter and cheese made from heavily contaminated milk would probably be safe and, in any event, could be stored until sufficient decay had taken place.

\section{REFERENCES}

Anderson, E. C., Schuch, R. L., Fisher, W. R. \& Langham, W. (1957). Science, 125, 1273.

Brown, M. S. (I950). F. Hered. 4I, II 5 .

Chamberlain, A. C. \& Chadwick, R. C. (1953). Neucleonics, Ir, 22.

Chamberlain, A. C., Loutit, J. F., Martin, R. P. \& Russell, R. S. (I955). The Behaviour of ${ }^{131}$ I, ${ }^{89} \mathrm{Sr}$ and ${ }^{90} \mathrm{Sr}$ in Certain Agricultural Food Chains. Conference Paper 8/P/393, United Kingdom Atomic Energy Authority Conference on Peaceful Uses of Atomic Energy.

Comar, C. L., Russell, R. S. \& Wasserman, R. H. (1957). Science, 126, 485.

Hood, S. L. \& Comar, C. L. (1953). Metabolism of Cesium 137 in Laboratory and Domestic Animals. Report ORO-9I United States Atomic Energy Commission.

Lapp, R. E. (I955). Bull. atom. Scient. I1, 6.

Loutit, J. F. \& Russell, R. S. (1955). Vet. Rec. 67, Iо12.

Parker, H. M. (1950). Tolerable Concentration of Radio-iodine on Edible Plants. Report D. 2907 United States Atomic Energy Commission.

Singleton, R. W. (1955). Effects of Continuous Gamma Radiation on Corn. Report U. I391 United States Atomic Energy Commission.

Sparrow, A. H. \& Christensen, E. (1953). Rep. Brookhaven Lab. BNL-1 588.

U.S. Atomic Energy Commission (1950). Chemistry, 24, 2.

Wright, S. (1950). 7. cell. comp. Physiol. 35, Suppl. r, p. I87. 